\title{
Coordinated Androgen and Estrogen-receptor microRNA 26 Directive in Breast and Prostate Tumour
}

\author{
Santosh Fattepur ${ }^{1, *}$, Kiran Chanabasappa Nilugal', Ibrahim Abdullah', Nagaraja Sreeharsha ${ }^{2,3}$, \\ Md. Khalid Anwer ${ }^{4}$, Syed Mohammed Basheeruddin Asdaq ${ }^{5}$
}

${ }^{1}$ School of Pharmacy, Management and Science University, Seksyen 13, Shah Alam, Selangor, MALAYSIA. ${ }^{2}$ Department of Pharmaceutical Sciences, College of Clinical Pharmacy, King Faisal University, Al-Ahsa, SAUDI ARABIA. ${ }^{3}$ Department of Pharmaceutics, Vidya Siri College of Pharmacy, Bengaluru, Karnataka, INDIA.

${ }^{4}$ Department of Pharmaceutics, College of Pharmacy, Prince Sattam Bin Abdulaziz University, Al-Alkharj, SAUDI ARABIA.

${ }^{5}$ Department of Pharmacology, College of Pharmacy, AIMaarefa University, Riyadh, SAUDI ARABIA.

\begin{abstract}
MiR-26 is a miRNA tumour suppressor that is frequently dysregulated in many tumour tissues and lines of tumour cells. Androgen and Estrogen receptor (AR \& ER) were evolving as a target to examine among hormone proteins since it appears to show a part at numerous phases of growth of breast and prostate cancers. For that kind of reason, $A R$ and $E R$ are becoming very relevant in recent times. Although its position remains problematic in medical care, the various finding had demonstrated a link among microRNAs 26, a group of receptors of genetic expression, and cancer (AR \& ER), but there is still little evidence for the association among BC and PC miRNAs. The major goal of our study is to deliver $A R$ and ER pathways involved in the development of microRNAs 26. Moreover, the functional and structural analysis of microRNAs 26 concerning cancer and non-cancerous cells were also discussed briefly. Additionally, the gene for post-transcriptional regulatory functions in breast and prostate cancer of different dysfunctional miRNAs 26 and their medicinal properties were also presented.
\end{abstract}

Keywords: Breast cancer, Prostate cancer, microRNA 26, Androgen receptor (AR), Estrogen receptor (ER).

\section{INTRODUCTION}

MicroRNAs (miRNAs) is named as a collection of minor non-coded endogenous RNAs which even at the post-transcriptional stage negatively control receptor coded messenger RNAs (also called mRNAs). In the literary works, the resultant mechanism and the principal operation of a miRNA were simple and well defined. Matured miRNAs were single-stranded (SS) RNAs comprising of around 22 nucleotides, produced thru the consecutive processes of the Drosha and Dicer RNA slicing enzymes. ${ }^{1-3}$ from the broader non-coding principal or $1^{\circ}$ miRNAs (pri-miRNAs) and again from predecessor miRNAs (premiRNAs). The primary purpose of miRNAs is to move in and interfere in mRNA translation or to cause mRNA deterioration. Matured miRNAs were integrated into the RNA-inducing silencing complex in mammals (known as RISC).

The enabled RISC allows miRNAs to attach to the 39 untranslated areas of unique target mRNAs (39UTR) to inhibit translation and induce mRNA decay deprivation. ${ }^{46}$ The miRNAs and targeting mRNAs do not have a one-to-one relationship. Multiple mRNA targets can have a single miRNA. Predicting the targeted mRNAs of a miRNA is a daunting challenge, considering that accurate estimation is important for studying its functional behaviour and its interaction with disorders. The mechanism of originating
Submission Date: 02-05-2021; Revision Date: 20-06-2021; Accepted Date: 08-07-2021

DOI: 10.5530/ijper.55.3.146 Correspondence: Dr. Santosh Fattepur School of Pharmacy, Management and Science University, Seksyen 13, 40100 Shah Alam, Selangor, MALAYSIA.

Phone: +60 195960309, Email -dr_santosh@msu. edu.my

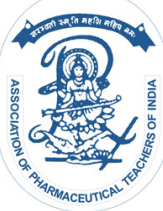

www.ijper.org 


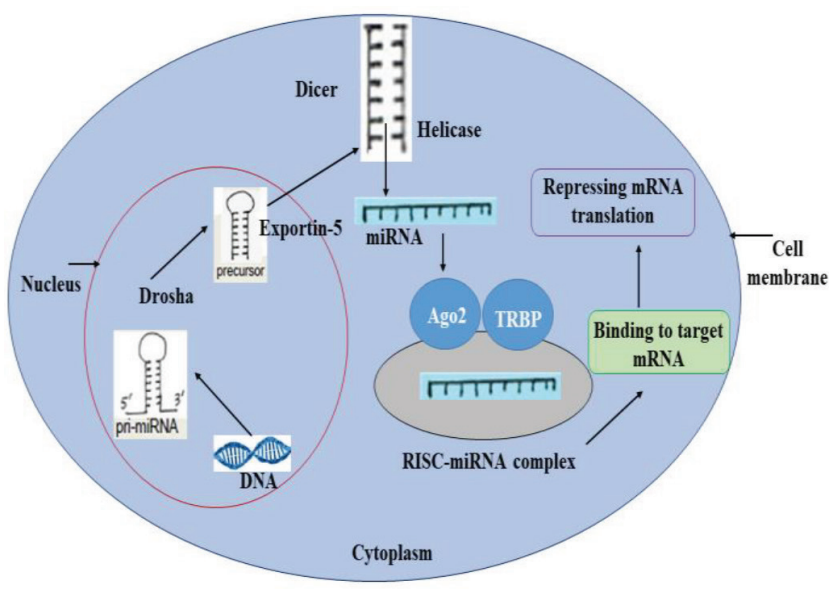

Figure 1: Mature miRNA biogenesis and its functional mechanism.

a micro-RNA molecule and its major function is shown in Figure 1.

\section{Origin and function of miRNA}

Blood cells and other tissues have been shown to relate to extra-cellular miRNAs. Pritchard et al. looked at 79 published solid cancer spreading miRNA biological markers and discovered nearly $58 \%$ of them was abundantly stated in one or even more blood cellular forms. In addition, they demonstrated the rate of the plasma miRNA genetic indicators are strongly associated with appropriate blood cell counts or hemorrhagic, indicating that miRNAs were primarily resultant from blood-based cells in serum/plasma. ${ }^{7}$ Relevant tissue-enriched miRNAs were also found in plasma, like liver-rich miRNA-122, muscular miRNA-133, heart-enrich miRNA-208 and brain-enrich miRNA-124. ${ }^{8-10}$ through three separate pathways, these miRNAs are released into extracellular space are (i) discharge from damaged cells as a consequence of tissue impairment, infection, necrosis/ cell death. (ii) Active release through membraneenclosed cell fragments known as micro-vesicles (MVs) that comprise detaching membranes and exosomes and, within physiological circumstances, were produced by nearly all cellular types. ${ }^{11-15}$ (iii) Active secretion through a protein-dependent mechanism that is $\mathrm{MV}$-free, RNA-binding. Recent research has shown that several RNA-binding factors, like higher-density lipoprotein (HDL) ${ }^{16}$ Argonaute 2 (AGO2), ${ }^{17,18}$ and nucleophosmin 1 (NPM1), ${ }^{19}$ are capable of combining with and delivering miRNAs outside of the cells. Stashing miRNAs through MVs and HDL-binding is effective and requires energy compared with traditional leakage. Active processes' extracellular miRNAs are intended to involve a regulatory function in biological systems.
The prevalent existence of extracellular miRNAs and their distribution constancy indicate a captivating feature of this miRNA originating from cells. Most secretory miRNAs, especially MV-free, protein-binding extracellular miRNAs, have yet to be fully understood. In recent times, the function of MV-encapsulated miRNAs within the control of physiological functions was examined and partially unveiled. Several studies have shown that miRNAs could be transmitted via MVs and then perform specific functions in recipient cells. These miRNAs tend to be a new component of cell adhesion, and extracellular miRNA-mediated cross-talk can proceed. These miRNAs tend to be a revolutionary element of transcriptional activation, and cross-talking facilitated by extra-cellular miRNAs might deliver a novel insight on how abnormal conditions are induced.

\section{Role of miRNA in normal and cancer cell progression}

Many tumours have the ability to influence their micro - environment in order to promote their survival, development, and intrusion. For example, via secreted molecules and paracrine signaling, cancerous cells can transform the surrounding cells in the body from the original maintain homeostasis conditions to neo-plastic existence of cancer. Contact in tumour microenvironment among tumour- and normal-cells has been exposed to be perilous for the growth of tumour. ${ }^{20}$ Current reviews have shown that tumour cells' extracellular miRNAs can influence their environment and are intimately invested in tumourigenesis. Exosome miRNA-92a, originating from the leukaemia-based cells $\mathrm{K} 562$, was found to pass into the nucleus of normal cells by Umezu et al. Umezu et al. demonstrated that exosome miRNA-92a, originating from K562 leukaemia cells, transmitted to human umbilical vein endothelial cells (HUVECs), specifically mediated the integrin alp5 targeting gene, resulting in increased movement and tube forming of endothelial cells. ${ }^{21}$ A study in 2014 also showed that cancer-secreting miRNA-214 was adequately transmitted through MVs and effectively dysregulated phosphatase and tensin homolog (PTEN) into activated mouse peripheral CD4+ $\mathrm{T}$ cells, resulting in the development of Treg development. ${ }^{22}$ Treg extension mediated by the cancer cell-secretion based miRNA-214 can further weaken the immune system and increase cancer implantation or development in mice. After MV distribution of anti-miRNA-214 antisense oligo-nucleotides (ASOs) to tumours, this process may be changed. ${ }^{22}$ These findings strongly indicate that tumour cells deliberately assemble miRNAs into MVs and move them to the environments in order to 
modify tumour-stromal conditions, thereby promoting tumour growth. These findings strongly indicate that tumour cells deliberately bundle miRNAs into MVs and move them to the environments, altering tumourstromal conditions and facilitating cancerous cells survival and malignancy. Recent times, it has partially unveiled the mechanisms regulating tumour exosome release. Pyruvate kinase type M2 (PKM2) that is an enzyme involved in cancer cell dependence on aerobic glycolysis, has been found to help the release of tumour cell exosomes. ${ }^{24}$ PKM2 is elevated and phosphorylated in cancers, and the phosphorylated PKM2 acted as a receptor kinase, phosphorylating synaptosome-related protein-23 (SNAP-23) at Ser95. In chance, this allowed the development of these complexes of soluble N-ethylmaleimide-sensitive fusion factor attachment protein receptor (SNARE) to enable exosome proclamation. ${ }^{23}$ It's been generally believed that tumour-derived extracellular miRNAs, as effective controllers secreted by tumour cells, had a direct influence on the environment normal administrations, supporting the creation of tumour.

\section{Structure distribution of miRNA-26}

The only three subcategories of the hsa-miRNA-26 group are miRNA-26a-1, 2, 26b, which are present on chromosome numbers 3, 12 , and 2, respectively. MiRNA-26a-1 and 2 mature miRNAs have the similar sequence, by the exclusion of two separate miRNA26b-2 mature miRNA-26b nucleotides. Pre-miRNA-26 by a stem-looping framework (Figure 2) was transformed by a sequence of intra-nuclear and intra-cytoplasm

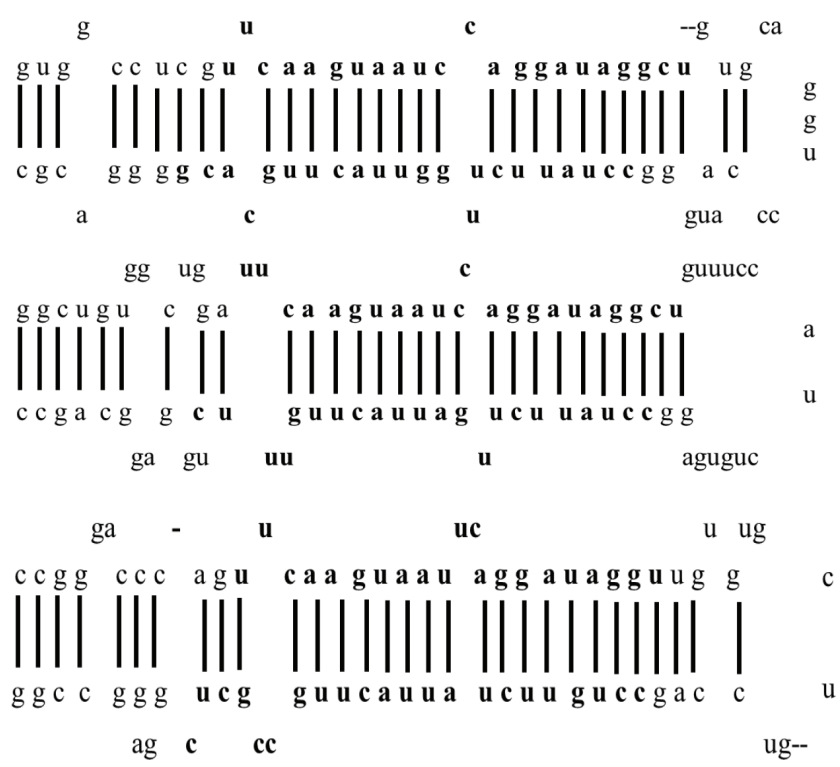

Figure 2: Stem-based loop assembly of pre-miRNA-26. (i) PremiRNA-26a-1, (ii) pre-miRNA-26a-2, and (iii) pre-miRNA-26b. enzymes through mature miRNA-26. With such a seed domain of about 6 to 7 nucleotides, the mature miRNA-26 was 21-22 nucleotides long. The miRNA-26 seeded area series, an essential area for linking to targets mRNA, was extremely congruent among groups of various genera. During growth, production and tumour growth, various tumours and surrounding tissue display specific miR-26 expression, and miR-26 can part in different biological systems via imperfect sequence complementarity linking amid the seed domain and the targeted mRNA 3'UTR. MiR-26 can inhibit specific gene translation and reduce target gene-coding protein expression patterns. In gene regulation for gene editing, miRNA has several target genes, which makes it essential in carcinogenesis and cancer treatment. It was found that in many tumours, miRNA-26 expression was distorted and has distinct roles in various tumours.

\section{miRNA-26 and cancers: down- and up-direction}

Extremely, findings were also exposed that different tumour types, miRNAs were implicated in cell proliferation and function as oncogenesis or tumour-suppressive genes. Oncomir, including the miRNA-17-92 cluster, are oncogenesis miRNAs, whereas cancer-suppressive miRNAs, like miRNA-34, are tumour-suppressive miRNAs. As mentioned above, in a range of tumours, miRNA-26 expression becomes dysfunctional, however its roles remain unclear.

\section{Down-regulated miRNA-26}

MiR-26 is dysregulated in a number of cancer kinds and might have cancer-suppressive properties throughout tumour growth. Wang et al. stated that miR-26 expression is down-regulated in bladder tumour in classes T1 (distinguished grade 1-2) and T2 (discriminated grade 1-3). In the $\mathrm{T} 2$ group of bladder tumours, miRNA-26 was the most important of four down-regulating miRNAs. Despite of cancer stage or tumour progression, all bladder tumours display a decrease in expression of four miRNAs. As a result, miR-26 might be a beneficial marker in the analysis of bladder tumour.20 E2-repressed miR-26a and miR-181a controlled various genetic variants with cancer progression through oestrogen receptors and transcription factors, according to Maillot et al. Furthermore, in breast tumour patients who have undergone anti-estrogen adjuvant treatment, miRNA expression was controlled. This modulation showed that miRNA was associated with breast cancer anti-estrogen tolerance. 21 miRNA-26a was recognized to be down-regulating in breast tumour samples and cells, and it has been found to cause apoptosis via endo-genous and exo-genous routes triggered through 
caspase-8 and 9, and also direct requisite into the 3'-UTR of MTDH and EZH2. MCF7 cells' ability to colonize in vitro and load tumours in vivo is harmed by MiR-26.22

\section{Up-regulated miRNA-26}

In different cancer kinds, wherever it operated as cancer suppressor gene miRNA, miR-26 expression reportedly reduced. Nevertheless, recent research has shown that miR-26 expression is rise in tumours like glioma. ${ }^{23,24}$ Huse et al. stated that higher-grade glioma (the most predominant investigative type of initial brain cancer in the adult-based people) and specifically embattled PTEN were over-expressed with miR-26a. In a group of human higher-grade gliomas, miRNA-26a was often elevated by the DNA level and their over-expression is closely correlated by mono-allelic PTEN injury. In a related glioma model organism, overexpression of miR-26a that use the RCAS/tv-a scheme showed the miRNA-26a effectively suppressed the endo-genous PTEN receptor through necessary to three possible linking in PTEN 3'-UTR, encouraging tumour growth. As a result, miR-26 could be an oncomir in glioma. Particularly, the research through Huse et al. showed that miRNA-26a over-expression in LN-18 cell lines were reduced EZH2 and SMAD1 function, suggesting that throughout gliomagenesis the proteins of the protein molecules were efficiently controlled by miRNA. ${ }^{23}$

\section{miRNA-26 in non-cancer disorder}

miR-26 expression is not merely on impaired during tumourigenesis, but it can also be altered in non-tumour illnesses. Chronic cholestasis-induced primary bilateral cirrhosis (PBC) is often preceded by autoimmune disorders like rheumatoid arthritis and scleroderma. Padgett et al. confirmed the maximum of 35 different miRNAs are distorted within the pattern of miRNA appearance and also that miR-26a was among the miRNAs downcontrolled. These alternate miRNAs' projected targets have been linked to cell growth, programmed cell death, infection, oxidative stress, and metabolism, all of which are linked to the production of PBC. ${ }^{25} \mathrm{~A}$ function of miRNA-26 in non-cancer disorders are hitherto to be explained and more research have to be determined.

\section{miRNA-26 in normal tissue development}

Through their target genes, miRNAs show a perilous part in a quantity of biological functions. It was understood that miRNA-26 shows an important part in various tissues formation, development and cellular differentiation. In order to distinguish here between hepatocyte and the cholangiocyte, murine foetal hepatoblast cells could be induced and the function of miRNAs mostly throughout distinction progressions is changed. miRNA-23b clustering miRNAs like miR-26a has a incline of impact on the option of cellular fate throughout the liver of the foetal mouse by transforming the signal system of growth factor- $\beta$ (TGF $\beta$ ) or bone morphology gene receptor. In cholangiocytes, decreased amounts of miRNA-23b miRNAs are needed to permit TGF $\beta$ signaling and bile-based duct creation. ${ }^{26} 2 \mathrm{~b}$ miRNAs). In osteogenesis, some miRNAs control the proliferation and development of osteoblast cells in human adipose tissue stem cells. ${ }^{27}$ The role of miRNA-26 in myo-genicity was better understood through research into miRNA in normal tissue progress and expansion. The miRNA expression pattern of myogenesis was researched by Wong and Tellam. ${ }^{28}$ These scientists found six miRNAs in myotubes by 2 -fold or larger substantial alteration of expression.

As per the expression pattern, these miRNAs were split into three classes. During the process of myogenesis, miRNA-26a, an up-controlled miRNA in clustered II, was up-controlled more progressively. Creatine kinase activity risen dramatically during myogenesis when miR-26a was overexpressed in murine myogenic $\mathrm{C}_{2} \mathrm{C}_{12}$ cells. Expression levels of myoD and myogenin mRNA was also up-controlled, and EZH2 were recognized as a possible miR-26a target. miRNA-26a over-expression reduced EZH2 mRNA appearance and inhibited the action of the build of a luciferase reporter merged with EZH2's 3'UTR. Since up-regulation of miR-26a is necessary for deadly differentiation the -ve controller of myogenesis EZH2 is suppressed quickly and effectively, facilitating myogenesis and terminal divergence. ${ }^{28}$ miRNA-26 has been discovered to show a significant part in normal tissue development and growth, and also cellular proliferation; nevertheless, the function is unclear.

\section{MiRNA 26 and Its Potential Targets}

\section{Targeting of androgen receptor (AR) by microRNAs in prostate tumour}

The specific directing of the AR 3' UTR through miRNAs is a prominent aspect of this interplay. Indeed, a recent study reported that miRNAs are expected to be more strongly dominated by the AR 3'UTR than all of another PCa driver genes and even within the top 5 percent of total regulatory proteins. ${ }^{29}$ The photoactivated ribonucleoside-improved cross-linking immunoprecipitation of the Argonaute receptor method was used to classify 147 miRNA seeding sections in the AR 3'UTR, belonging to 71 miRNA families. Pertinently, 4 of a miRNAs recognized by Hamilton and colleagues 


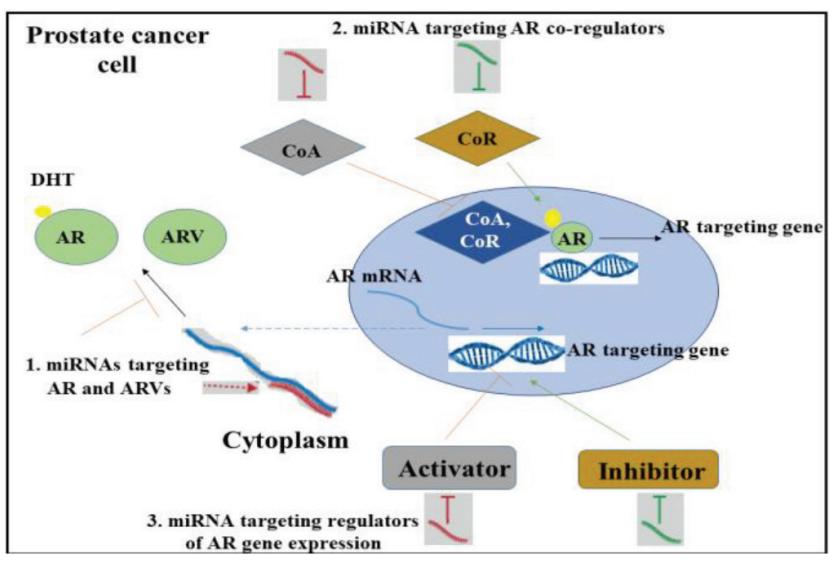

Figure 3: Mode of action and directive of AR expression through miRNA and its activity in prostate tumour cells.

namely, miRNA-9, 34c, 185, and 488 have subsequently been identified in two higher throughput sequencing shades intended at discovering new genes. Several other findings have considered unique AR-targeted miRNAs within a more focused way in accumulation to these unbiased approaches. Stling, Lin, Kumar et al. reported that, in comparison to basic target of the $3^{\prime} \mathrm{UTR}$, miRNA control of the AR through the $5^{\prime}$ UTR and the coded area have also been described. ${ }^{30-32}$ The mode of actions through that miRNAs effect the AR signaling were exemplified in Figure 3.

We suggest that a series of distinct parameters can be used to prioritize the biological significance of this AR-targeted miRNAs. First, in numerous studies utilizing multiple in vitro studies, miRNAs which have been established were possible to had higher biological significance in PCa. Secondly, it was established that cell transfection of miRNA imitators could induce nonphysiological action of miRNA; thus, research which had documented AR directing both utilizing miRNA imitators and antagonists are prioritized. Thirdly, considering that prostate cancers are 'addicted' to AR, ${ }^{33}$ oncogenesis selection pressure will be required to down regulation biologically important miRNAs regulating AR. Indeed, as opposed to non-malignant prostate areas, a variety of AR-directing miRNAs were originated to be dysregulated in prostate cancers. Although, our research miRNA appearance studies in The Cancer Genome Atlas and Memorial Sloan-Kettering Cancer Center $^{34}$ frequently dispute the reported tumour correlations. Eventually, it would be predicted that in clinical samples, biologically significant miRNAs were contrarywise associated by AR receptor expression. Indeed, we found a link between miRNA-145, 205, 34a, and 31 in the TCGA cohort. We suspect that decreased expression in this disorder of at minimum the subclass of this miRNAs was a crucial enabling of expression level and behavior of AR.

\section{Targeting of androgen receptor (AR) by microRNAs in breast tumour}

microRNAs were perhaps the mostly studied noncoded RNAs, and they provide consumers with a wide group of single-strand RNAs with short (19-24 nucleotides) that show a part in various of biochemical functions with cell growth, death, proliferation, and strain reaction. ${ }^{35,36}$ Detecting a 2-7 nucleotide "seed-region" within the targeted mRNA, that could be located within the $30-\mathrm{UTR},{ }^{37} 50-\mathrm{UTR},{ }^{38}$ or coded region. ${ }^{39}$ Their processes necessary on gene expression is achieved by regulating mRNA targeted transcription that can outcome in both down - regulation and up - regulation of the gene encoding. ${ }^{39,40}$ Fabbri et al. presented a crucial turning point by demonstrating for the $1^{\text {st }}$ period the potential of miRNAs secretory through tumour-derived exosomes (TEX) to performance as paracrine inhibitors of the particular protein superfamily, indicating a role in the tumour micro-environment association and a newly potential targeting for the management of tumour. ${ }^{41}$ Many groups followed suit, exploring the part of miRNAs in tumour communication, growth, and spreading. Most lately, it was shown that breastcancer TEX can transport precursor miRNAs (premiRNAs) mixed with dicer, TRBP, and AGO2 receptors, demonstrating a cellular-independent capability to integrate pre-miRNAs to matured phase, leading to its understanding of a cellular-autonomous TEX. ${ }^{42}$

Although a numerous study has suggested a connection among miRNAs and AR in PC, ${ }^{43-47}$ there will still be limited proofs of miRNAs' function in regulating $A R$ expression in BC. Nakano et al. described miRNA-363 as an androgen-induced miRNA for the very firsttime using miRNA Polymerase Chain reaction (PCR) Arrays. They discovered a potential androgen-associated feedback looping affecting the gene IQWD1 (IQ motif and WD repeats- 1) and miRNA-363 in MCF-7 BC cells: IQWD1 were downregulated through miRNA-363 when androgen levels were low, but this negative regulation did not take place after DHT treatment. Surprisingly, IQWD1 plays a role in shielding AR enzymes from proteasome degradation. Androgens tended to intercede a -ve association among miRNA-let-7a expression and the expressing of the target transcription factors CMYC and KRAS within ARC/ER- models. ${ }^{48}$

A huge rise in let-7a activity was significantly in the MA MDA-MB 453 and the TNBC MDA-MB 231 cells controlled by DHT, along with a decline in CMYC and KRAS. IHC reported the negative association in $\mathrm{BC}$ 


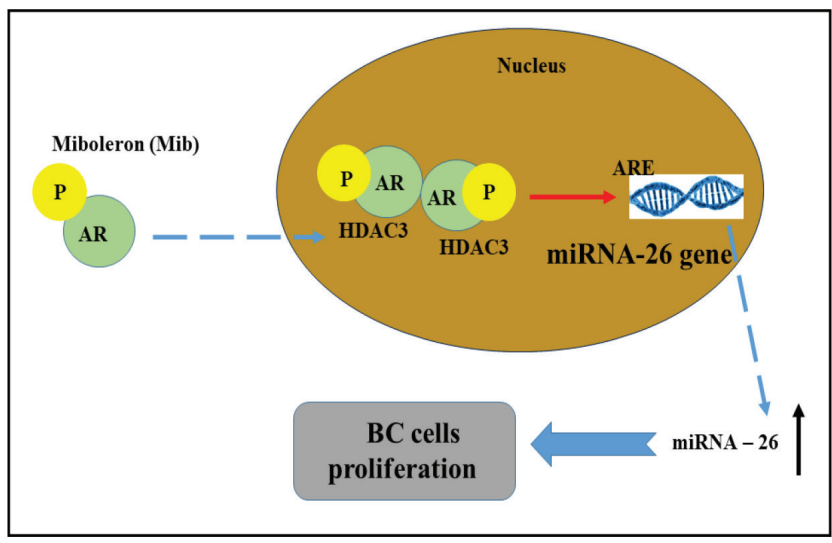

Figure 4: Direction of onco-miRNA-21 through AR transcriptional suppression in BC. Upon miboleron (Mib) linking the AR undertakes a conformational modification and translocate into the nucleus and activate the $\mathrm{BC}$ cell proliferation.

tissues, pointing to a novel androgen-stimulated AR energizing signal mechanism which specifically upregulated let-7a while -vely regulating CMYC and KRAS, impeding ARC/ER- cell growth. ${ }^{49}$ Figure 4 demonstrated that enabled AR acts as a transcriptional antagonist of miR-26 transcription using the artificial androgen miboleron (Mib) and chromatin immunoprecipitation (ChIP) study. AR was capable to attach the miR-26 proximal promoters in a specific ARE series, including the deployment of HDAC3 as a cofactor in AR-associated transcription activation.

\section{Targeting of estrogen receptor (ER) by microRNAs in prostate and breast tumour}

The tumour suppressor (TS) miRNA miR-26a-5p is often dysregulated in cancer tissues and cells. ${ }^{50-54}$. The depletion of miRNA-26a-5p increased propagation, relocation patterns ability, and intrusiveness in prostate tumour cells. ${ }^{55}$ Re-expression of miRNA-26a-5p in the androgen-independent PC3 cancer cells, on the other hand, revived TS action through significantly reduces cell growth and suppressing wnt5a. ${ }^{56}$ Likewise, re-expression of miRNA-26a-5p in PC3 cell line suppressed LARP protein-1 through preventing microbial invasiveness $^{52}$ or suppressing the G1 or $S$ transition via attacking the cell-based cycle controlling system. ${ }^{57}$ In a murine prototypical of hepatocellular carcinoma, re-expression of miRNA replacement decreased cancer mass production within the liver. ${ }^{58}$ Overall, the study clearly confirms the theory that miRNA-26a-5p's cancer suppresser genes function is dependent on the ability to suppress cancer-related genes. Since a single miRNA may target expression of genes at once, it's likely which more associations between miRNA-26a-5p was and mRNAs were identified, it'll be easier to pinpoint the paths impacted through its cancer suppresser genes action.

The miRNA expression range in solid tumours, such as the prostate, colon, liver, etc., varies from that in regular tissues. ${ }^{59}$ While the exact sequence of events that leads to breast cancers were unclear, lifelong oestrogen revelation is generally recognized as a significant danger issue for breast tumour. ${ }^{60} \mathrm{E} 2$ was revealed to be highly toxic in human breast epithelial cells by some researchers. ${ }^{61-63}$ In mammals, though, epidemiological evidence contradicting E2's carcinogenicity was already published. ${ }^{64}$ Interestingly, no studies examine the consequence of E2 on universal miRNA expression in breast tumour cells have been reported. In human breast tumour, irregular shapes of miRNA transcription were identified, ${ }^{65-68}$ and recently listed. ${ }^{69}$ Firstly, miRNA analysis in breast tumour found that miRNA expression differed from another well-established indicators of breast tumour phase and diagnosis, such as ER- and PR expression, cancer period, number of healthy lymph nodes, and vascularization. ${ }^{70}$ ErbB2+ versus ER+ tumours were also linked to different miRNA expression patterns. ${ }^{71}$ Patients with decreased miR-126, miR-206, or miR-335 expression in their breast tumours, irrespective of ER or ErbB2 status, have been shown to have a lower survival rate. Patients with decreased miRNA-126, 206, or 335 levels in their breast tumours, irrespective of ER or ErbB2 position, have been shown to have a lower survival rate. ${ }^{72}$

In silico research has established a variety of genes associated in tumour progression as targets of lightly regulated miRNAs in breast cancer, ${ }^{73}$ but some of these genes have been laboratory experiments confirmed. Antisense to miR-21 inhibited MCF-7 breast cancer cell cells proliferation and as cancer xenografts in mouse through controlling $\mathrm{Bcl}-2$, according to a recent survey. ${ }^{74}$ Overexpression of miRNA-21 in MCF-7 cell lines enhanced soft-agar colony creation, signifying that these cells are more oncogenic. ${ }^{75}$ miRNA-21 decreases Pdcd 4 protein levels by binding to a seed portion within the 3' UTR of an induction of apoptosis 4 (PDCD4) gene. ${ }^{75}$ miRNA-17-5p controls the breast cancer oncoprotein AIB1/SRC-3/ NCOA3, and it was a mutual association among lower miR-17-5p and higher AIB1 in tumour cells. ${ }^{76}$ Overexpression of miRNA-17-5p inhibited E2-stimulated multiplication of MCF-7 breast tumour cells, suggesting that miRNA-17-5p can show a significant part in breast cancer. ${ }^{76}$ Gene expression of miRNA-125a and miRNA-125b impaired the anchorage-independent development of ER-ve/ ErbB2over-expressing SKBR3 tumour cells by lowering 
ERBB2 and ERBB3 mRNA and receptor expression, inhibiting secretion of ERK1/2 and AKT, and inhibiting the anchorage-independent development of ER-ve/ ErbB2-overexpressed SKBR3 tumour cells. ${ }^{77}$ In MCF-7 cells, miR-206 controls ER mRNA equilibrium, and miRNA-206 transcription is greater in ER negative MDA-MB-231 cells. ${ }^{78}$

\section{CONCLUSION}

Because of the complexities of the miRNA-26 biogenesis process, androgen modulation of miRNA synthesis can take many forms, including and expanding beyond gene activation. The effects miRNAs-26, on the other hand, can influence AR and ER behavior through a variety of mechanisms. Direct mRNA targeting, suppression of its various genes modulation of it signaling molecules, and cofactors Dicer, a cropped enzyme, is essential for androgen initiation of genes that are being targeted AR: miRNA has a higher degree of difficulty. Non-canonical pathways offer opportunities for cross-talk. Post-translational changes to Drosha or Dicer are bypassed components of the pathway, the little-known process Lowering of the AR and ER 30UTR and the modulated abundance a splice version in AR during disease development. The miRNAnome can be fine-tuned in a receptive and complex manner thanks to the combination of integrated-step miRNA biosynthetic pathways and the AR and ER signaling axis, which has consequences for expanded ceRNA channels. PCa and other tumours demonstrate dysfunction of this delicate equilibrium, which results in PCa-specific, AR-linked miRNA fingerprints for fluid biopsy and miRNA objectives for beneficial treatment. Certain that AR is needed for continuing PCa development and enhancement in the nonappearance of mixing androgens, it's no surprise which AR directing tumour repressive miRNAs is frequently lost as $\mathrm{PCa}$ progresses, while AR-promoting miRNAs is generally obtained. Furthermore, AR-directed miRNA signs were enhanced for miRNAs that influence its effectors and coagulation factors, participating in signaling feedback mechanisms that can intensify or limit signaling. Furthermore, although the potential of miRNAs-26 to drive confrontation to ADT and another PCa treatments is becoming more commonly recognized, it is still under-investigated experimentally due to sample investigation from limited patient populations, wellknown drawbacks of PCa-based cells, and major inter or intra-tumour diversity.

\section{ACKNOWLEDGEMENT}

We would like to express our appreciation to Uma Chandur, Principal, Vidya Siri College of Pharmacy, Bangalore for proofreading this review article.

\section{CONFLICT OF INTEREST}

The authors declare that there is no conflict of interest.

\section{ABBREVIATIONS}

AR: Androgen Receptor; ER: Estrogen Receptor; RISC: RNA-inducing silencing complex; MVs: MicroVesicles; HDL: Higher-Density Lipoprotein; AGO2: Argonaute 2; NPM1: Nucleophosmin 1; HUVECs: Human Umbilical Vein Endothelial Cells; PTEN: Phosphatase and tensin homolog; ASOs: Antisense oligo-nucleotides; PKM2: Pyruvate kinase type M2; PBC: Primary Bilateral Cirrhosis; TEX: Tumourderived Exosomes; PCR: Polymerase Chain reaction; Mib: Miboleron; ChIP: Chromatin Immunoprecipitation; TS: Tumour Suppressor.

\section{REFERENCES}

1. Kim YK, Kim VN. Processing aof intronic microRNAs. EMBO J. 2007;26(3):775-83. doi: 10.1038/sj.emboj.7601512, PMID 17255951.

2. Lee Y, Ahn C, Han J, Choi H, Kim J, Yim J, Lee J, Provost P, Rådmark O, Kim S, Kim VN. The nuclear RNase III Drosha initiates microRNA processing. Nature. 2003;425(6956):415-9. doi: 10.1038/nature01957, PMID 14508493.

3. Du T, Zamore PD. microPrimer: the biogenesis and function of microRNA. Development. 2005;132(21):4645-52. doi: 10.1242/dev.02070, PMID 16224044.

4. Carthew RW. Gene regulation by microRNAs. Curr Opin Genet Dev. 2006;16(2):203-8. doi: 10.1016/j.gde.2006.02.012, PMID 16503132.

5. Filipowicz W. RNAi: the nuts and bolts of the RISC machine. Cell. 2005;122(1):17-20. doi: 10.1016/j.cell.2005.06.023, PMID 16009129.

6. Ambros V. The functions of animal microRNAs. Nature. 2004;431(7006):350-5. doi: 10.1038/nature02871, PMID 15372042.

7. Ambros V, Bartel B, Bartel DP, Burge CB, Carrington JC, Chen X, Dreyfuss G, Eddy SR, Griffiths-Jones S, Marshall M, Matzke M, Ruvkun G, Tuschl T. A uniform system for microRNA annotation. Rna. 2003;9(3):277-9. doi: 10.1261/rna.2183803, PMID 12592000.

8. Kotz S, Kozubowski TJ, Podgórski K. Maximum likelihood estimation of asymmetric Laplace parameters. Ann Inst Stat Math. 2002;54(4):816-26. doi: 10.1023/A:1022467519537.

9. Hoaglin DC, Tukey JW. Checking the shape of discrete distributions. Exploring Data Tables, Trends and shapes. Biometrical J. 1987;29(2):345416.

10. Quesenberry CP, Hurst DC. Large sample simultaneous confidence intervals for multinomial proportions. Technometrics. 1964;6(2):191-5. doi: 10.1080/00401706.1964.10490163

11. Stuart JM, Segal E, Koller D, Kim SK. A gene-coexpression network for global discovery of conserved genetic modules. Science. 2003;302(5643):249-55. doi: 10.1126/science.1087447, PMID 12934013.

12. Pál C, Papp B, Lercher MJ. An integrated view of protein evolution. Nat Rev Genet. 2006;7(5):337-48. doi: 10.1038/nrg1838, PMID 16619049.

13. Vaquerizas JM, Kummerfeld SK, Teichmann SA, Luscombe NM. A census of human transcription factors: function, expression and evolution. Nat Rev Genet. 2009;10(4):252-63. doi: 10.1038/nrg2538, PMID 19274049. 
14. Wang D, Qiu C, Zhang H, Wang J, Cui Q, Yin Y. Human microRNA oncogenes and tumor suppressors show significantly different biological patterns: from functions to targets. PLOS ONE. 2010;5(9):e13067. doi: 10.1371/journal. pone.0013067, PMID 20927335.

15. Hirsh $A E$, Fraser HB. Protein dispensability and rate of evolution. Nature. 2001;411(6841):1046-9. doi: 10.1038/35082561, PMID 11429604.

16. Zhang R, Peng $Y$, Wang W, Su B. Rapid evolution of an X-linked microRNA cluster in primates. Genome Res. 2007;17(5):612-7. doi: 10.1101/ gr.6146507, PMID 17416744

17. Zhang $Q$, Lu M, Cui $Q$. SNP analysis reveals an evolutionary acceleration of the human-specific microRNAs. Nat Proceedings. 2008;1:1. doi: 10.1038/ npre.2008.2127.1.

18. Calin GA, Dumitru CD, Shimizu M, Bichi R, Zupo S, Noch E, Aldler H, Rattan S, Keating M, Rai K, Rassenti L, Kipps T, Negrini M, Bullrich F, Croce CM. Frequent deletions and down-regulation of micro-RNA genes miR15 and miR16 at 13q14 in chronic lymphocytic leukemia. Proc Natl Acad Sci U S A. 2002;99(24):15524-9. doi: 10.1073/pnas.242606799, PMID 12434020.

19. Calin GA, Sevignani C, Dumitru CD, Hyslop T, Noch E, Yendamuri S, Shimizu M, Rattan S, Bullrich F, Negrini M, Croce CM. Human microRNA genes are frequently located at fragile sites and genomic regions involved in cancers. Proc Natl Acad Sci U S A. 2004;101(9):2999-3004. doi: 10.1073/ pnas.0307323101, PMID 14973191.

20. Wang G, Zhang H, He H, Tong W, Wang B, Liao G, Chen Z, Du C. Upregulation of microRNA in bladder tumor tissue is not common. Int Urol Nephrol. 2010;42(1):95-102. doi: 10.1007/s11255-009-9584-3, PMID 19475496.

21. Maillot $G$, Lacroix-Triki M, Pierredon $S$, Gratadou L, Schmidt $S$, Bénès $V$, Roché H, Dalenc F, Auboeuf D, Millevoi S, Vagner S. Widespread estrogendependent repression of microRNAs involved in breast tumor cell growth. Cancer Res. 2009;69(21):8332-40. doi: 10.1158/0008-5472.CAN-09-2206, PMID 19826037.

22. Zhang B, Liu XX, He JR, Zhou CX, Guo M, He M, Li MF, Chen GQ, Zhao Q. Pathologically decreased miR-26a antagonizes apoptosis and facilitates carcinogenesis by targeting $\mathrm{MTDH}$ and $\mathrm{EZH} 2$ in breast cancer. Carcinogenesis. 2011;32(1):2-9. doi: 10.1093/carcin/bgq209, PMID 20952513.

23. Huse JT, Brennan C, Hambardzumyan D, Wee B, Pena J, Rouhanifard SH, Sohn-Lee C, le Sage C, Agami R, Tuschl T, Holland EC. The PTENregulating microRNA miR-26a is amplified in high-grade glioma and facilitates gliomagenesis in vivo. Genes Dev. 2009;23(11):1327-37. doi: 10.1101/gad.1777409, PMID 19487573.

24. Kim H, Huang W, Jiang X, Pennicooke B, Park PJ, Johnson MD. Integrative genome analysis reveals an oncomir/oncogene cluster regulating glioblastoma survivorship. Proc Natl Acad Sci U S A. 2010;107(5):2183-8. doi: 10.1073/pnas.0909896107, PMID 20080666.

25. Padgett KA, Lan RY, Leung PC, Lleo A, Dawson K, Pfeiff J, Mao TK, Coppel RL, Ansari AA, Gershwin ME. Primary biliary cirrhosis is associated with altered hepatic microRNA expression. J Autoimmun. 2009;32(3-4):246-53. doi: 10.1016/j.jaut.2009.02.022, PMID 19345069.

26. Rogler CE, LeVoci L, Ader T, Massimi A, Tchaikovskaya T, Norel R, Rogler LE. MicroRNA-23b cluster microRNAs regulate transforming growth factor-beta/ bone morphogenetic protein signaling and liver stem cell differentiation by targeting Smads. Hepatology. 2009;50(2):575-84. doi: 10.1002/hep.22982, PMID 19582816.

27. Itoh T, Nozawa Y, Akao Y. MicroRNA-141 and-200a are involved in bone morphogenetic protein-2-induced mouse pre-osteoblast differentiation by targeting distal-less homeobox 5. J Biol Chem. 2009;284(29):19272-9. doi: 10.1074/jbc.M109.014001, PMID 19454767.

28. Wong CF, Tellam RL. MicroRNA-26a targets the histone methyltransferase Enhancer of Zeste homolog 2 during myogenesis. J Biol Chem. 2008;283(15):9836-43. doi: 10.1074/jbc.M709614200, PMID 18281287.

29. Hamilton MP, Rajapakshe KI, Bader DA, Cerne JZ, Smith EA, Coarfa C, Hartig SM, McGuire SE. The landscape of microRNA targeting in prostate cancer defined by AGO-PAR-CLIP. Neoplasia. 2016;18(6):356-70. doi: 10.1016/j.neo.2016.04.008, PMID 27292025.

30. Östling P, Leivonen SK, Aakula A, Kohonen P, Mäkelä R, Hagman Z, Edsjö A, Kangaspeska S, Edgren H, Nicorici D, Bjartell A, Ceder Y, Perälä M, Kallioniemi $O$. Systematic analysis of microRNAs targeting the androgen receptor in prostate cancer cells. Cancer Res. 2011;71(5):1956-67. doi: 10.1158/0008-5472.CAN-10-2421, PMID 21343391.

31. Lin PC, Chiu YL, Banerjee S, Park K, Mosquera JM, Giannopoulou E, Alves P, Tewari AK, Gerstein MB, Beltran H, Melnick AM, Elemento O, Demichelis F, Rubin MA. Epigenetic repression of miR-31 disrupts androgen receptor homeostasis and contributes to prostate cancer progression. Cancer Res. 2013;73(3):1232-44. doi: 10.1158/0008-5472.CAN-12-2968, PMID 23233736.

32. Kumar B, Khaleghzadegan S, Mears B, Hatano K, Kudrolli TA, Chowdhury WH, Yeater DB, Ewing CM, Luo J, Isaacs WB, Marchionni L, Lupold SE. Identification of miR-30b-3p and miR-30d-5p as direct regulators of androgen receptor signaling in prostate cancer by complementary functional microRNA library screening. Oncotarget. 2016;7(45):72593-607. doi: 10.18632/ oncotarget.12241, PMID 27683042.

33. Coutinho I, Day TK, Tilley WD, Selth LA. Androgen receptor signaling in castration-resistant prostate cancer: a lesson in persistence. Endocr Relat Cancer. 2016;23(12):T179-97. doi: 10.1530/ERC-16-0422, PMID 27799360.

34. Taylor BS, Schultz N, Hieronymus H, Gopalan A, Xiao Y, Carver BS, Arora VK, Kaushik P, Cerami E, Reva B, Antipin Y, Mitsiades N, Landers T, Dolgalev I, Major JE, Wilson M, Socci ND, Lash AE, Heguy A, Eastham JA, Scher HI, Reuter VE, Scardino PT, Sander C, Sawyers CL, Gerald WL. Integrative genomic profiling of human prostate cancer. Cancer Cell. 2010;18(1):11-22. doi: 10.1016/j.ccr.2010.05.026, PMID 20579941.

35. Bartel DP. MicroRNAs: genomics, biogenesis, mechanism, and function. Cell. 2004;116(2):281-97. doi: 10.1016/s0092-8674(04)00045-5, PMID 14744438.

36. Kozomara A, Griffiths-Jones S. miRBase: integrating microRNA annotation and deep-sequencing data. Nucleic Acids Res. 2011;39(Database issue):D152-7. doi: 10.1093/nar/gkq1027, PMID 21037258.

37. Lewis BP, Burge CB, Bartel DP. Conserved seed pairing, often flanked by adenosines, indicates that thousands of human genes are microRNA targets. Cell. 2005;120(1):15-20. doi: 10.1016/j.cell.2004.12.035, PMID 15652477.

38. Lytle JR, Yario TA, Steitz JA. Target mRNAs are repressed as efficiently by microRNA-binding sites in the 5' UTR as in the 3' UTR. Proc Natl Acad Sci U SA. 2007;104(23):9667-72. doi: 10.1073/pnas.0703820104, PMID 17535905.

39. Forman JJ, Legesse-Miller A, Coller HA. A search for conserved sequences in coding regions reveals that the let-7 microRNA targets Dicer within its coding sequence. Proc Natl Acad Sci U S A. 2008;105(39):14879-84. doi: 10.1073/pnas.0803230105, PMID 18812516.

40. Vasudevan S, Tong Y, Steitz JA. Switching from repression to activation: microRNAs can up-regulate translation. Science. 2007;318(5858):1931-34. doi: 10.1126/science.1149460, PMID 18048652.

41. Fabbri M, Paone A, Calore F, Galli R, Gaudio E, Santhanam R, Lovat F, Fadda P, Mao C, Nuovo GJ, Zanesi N, Crawford M, Ozer GH, Wernicke D, Alder H, Caligiuri MA, Nana-Sinkam P, Perrotti D, Croce CM. MicroRNAs bind to toll-like receptors to induce prometastatic inflammatory response. Proc Natl Acad Sci U S A. 2012;109(31):E2110-6. doi: 10.1073/pnas.1209414109, PMID 22753494.

42. Melo SA, Sugimoto H, O'Connell JT, Kato N, Villanueva A, Vidal A, Qiu L, Vitkin E, Perelman LT, Melo CA, Lucci A, Ivan C, Calin GA, Kalluri R. Cancer exosomes perform cell-independent microRNA biogenesis and promote tumorigenesis. Cancer Cell. 2014;26(5):707-21. doi: 10.1016/j. ccell.2014.09.005, PMID 25446899.

43. Shi XB, Xue L, Yang J, Ma AH, Zhao J, Xu M, Tepper CG, Evans CP, Kung HJ, deVere White RW. An androgen-regulated miRNA suppresses Bak1 expression and induces androgen-independent growth of prostate cancer cells. Proc Natl Acad Sci U S A. 2007;104(50):19983-88. doi: 10.1073/ pnas.0706641104, PMID 18056640.

44. Epis MR, Giles KM, Barker A, Kendrick TS, Leedman PJ. miR-331$3 p$ regulates ERBB-2 expression and androgen receptor signaling in prostate cancer. J Biol Chem. 2009;284(37):24696-704. doi: 10.1074/jbc. M109.030098, PMID 19584056.

45. Ribas J, Ni X, Haffner M, Wentzel EA, Salmasi AH, Chowdhury WH, Kudrolli TA, Yegnasubramanian S, Luo J, Rodriguez R, Mendell JT, Lupold SE. miR-21: an androgen receptor-regulated microRNA that promotes hormone-dependent and hormone-independent prostate cancer growth. Cancer Res. 2009;69(18):7165-9. doi: 10.1158/0008-5472.CAN-091448, PMID 19738047. 
46. Cao P, Deng Z, Wan M, Huang W, Cramer SD, Xu J, Lei M, Sui G. MicroRNA-101 negatively regulates Ezh2 and its expression is modulated by androgen receptor and HIF-1 $\alpha / H I F-1 \beta$. Mol Cancer. 2010;9(1):108. doi: 10.1186/1476-4598-9-108, PMID 20478051.

47. Nadiminty N, Tummala R, Lou W, Zhu Y, Zhang J, Chen X, eVere White RW, Kung HJ, Evans CP, Gao AC. MicroRNA let-7c suppresses androgen receptor expression and activity via regulation of Myc expression in prostate cancer cells. J Biol Chem. 2012;287(2):1527-37. doi: 10.1074/jbc.M111.278705, PMID 22128178.

48. Nakano K, Miki Y, Hata S, Ebata A, Takagi K, Mcnamara KM, Sakurai M, Masuda M, Hirakawa H, Ishida T, Suzuki T, Ohuchi N, Sasano H. Identification of androgen-responsive microRNAs and androgen-related genes in breast cancer. Anticancer Res. 2013;33(11):4811-19. PMID 24222117.

49. Lyu S, Yu Q, Ying G, Wang S, Wang Y, Zhang J, Niu Y. Androgen receptor decreases $C M Y C$ and KRAS expression by upregulating let-7a expression in ER-, PR-, AR+ breast cancer. Int J Oncol. 2014;44(1):229-37. doi: 10.3892/ ijo.2013.2151, PMID 24172884

50. Chen J, Zhang K, Xu Y, Gao Y, Li C, Wang R, Chen L. The role of microRNA$26 \mathrm{a}$ in human cancer progression and clinical application. Tumour Biol. 2016;37(6):7095-108. doi: 10.1007/s13277-016-5017-y, PMID 27039398

51. Fukumoto I, Hanazawa T, Kinoshita T, Kikkawa N, Koshizuka K, Goto $Y$, Nishikawa R, Chiyomaru T, Enokida H, Nakagawa M, Okamoto Y, Seki N. MicroRNA expression signature of oral squamous cell carcinoma: functional role of microRNA-26a/b in the modulation of novel cancer pathways. $\mathrm{Br} J$ Cancer. 2015;112(5):891-900. doi: 10.1038/bjc.2015.19, PMID 25668004.

52. Kato M, Goto Y, Matsushita R, Kurozumi A, Fukumoto I, Nishikawa R, Sakamoto S, Enokida H, Nakagawa M, Ichikawa T, Seki N. MicroRNA26a/b directly regulate La-related protein 1 and inhibit cancer cell invasion in prostate cancer. Int J Oncol. 2015;47(2):710-18. doi: 10.3892/ijo.2015.3043, PMID 26063484.

53. Lin Y, Chen H, Hu Z, Mao Y, Xu X, Zhu Y, Xu X, Wu J, Li S, Mao Q, Zheng X, Xie L. miR-26a inhibits proliferation and motility in bladder cancer by targeting HMGA1. FEBS Lett. 2013;587(15):2467-73. doi: 10.1016/j. febslet.2013.06.021, PMID 23796420.

54. Zhu Y, Yu M, Li Z, Kong C, Bi J, Li J, Gao Z, Li Z. ncRAN, a newly identified long noncoding RNA, enhances human bladder tumor growth, invasion, and survival. Urology. 2011;77(2):510.e1-5. doi: 10.1016/j.urology.2010.09.022, PMID 21147498.

55. Guo K, Zheng S, Xu Y, Xu A, Chen B, Wen Y. Loss of miR-26a-5p promotes proliferation, migration, and invasion in prostate cancer through negatively regulating SERBP1. Tumour Biol. 2016;37(9):12843-54. doi: 10.1007/ s13277-016-5158-Z, PMID 27449037

56. Zhao S, Ye X, Xiao L, Lian X, Feng Y, Li F, Li L. MiR-26a inhibits prostate cancer progression by repression of Wnt5a. Tumour Biol. 2014;35(10):9725-33. doi: 10.1007/s13277-014-2206-4, PMID 24972966.

57. Erdmann K, Kaulke K, Rieger C, Salomo K, Wirth MP, Fuessel S. MiR-26a and miR-138 block the G1/S transition by targeting the cell cycle regulating network in prostate cancer cells. J Cancer Res Clin Oncol. 2016;142(11):2249-61. doi: 10.1007/s00432-016-2222-4, PMID 27562865.

58. Kota J, Chivukula RR, O'Donnell KA, Wentzel EA, Montgomery CL, Hwang HW, Chang TC, Vivekanandan P, Torbenson M, Clark KR, Mendell JR, Mendell JT. Therapeutic microRNA delivery suppresses tumorigenesis in a murine liver cancer model. Cell. 2009;137(6):1005-17. doi: 10.1016/j.cell.2009.04.021, PMID 19524505.

59. Volinia S, Calin GA, Liu CG, Ambs S, Cimmino A, Petrocca F, Visone R, lorio M, Roldo C, Ferracin M, Prueitt RL, Yanaihara N, Lanza G, Scarpa A, Vecchione A, Negrini M, Harris CC, Croce CM. A microRNA expression signature of human solid tumors defines cancer gene targets. Proc Natl Acad Sci U S A. 2006;103(7):2257-61. doi: 10.1073/pnas.0510565103, PMID 16461460.

60. Henderson BE, Feigelson HS. Hormonal carcinogenesis. Carcinogenesis. 2000;21(3):427-33. doi: 10.1093/carcin/21.3.427, PMID 10688862.

61. Russo J, Tahin Q, Lareef MH, Hu YF, Russo IH. Neoplastic transformation of human breast epithelial cells by estrogens and chemical carcinogens. Environ Mol Mutagen. 2002;39(2-3):254-63. doi: 10.1002/em.10052, PMID 11921196.
62. Russo J, Lareef MH, Tahin Q, Hu YF, Slater C, Ao X, Russo IH. 17ß-estradiol is carcinogenic in human breast Epithelial cells. J Steroid Biochem Mol Biol. 2002;80(2):149-62. doi: 10.1016/s0960-0760(01)00183-2, PMID 11897500.

63. Russo J, Fernandez SV, Russo PA, Fernbaugh R, Sheriff FS, Lareef HM, Garber J, Russo IH. 17-Beta-estradiol induces transformation and tumorigenesis in human breast epithelial cells. FASEB J. 2006;20(10):1622-34. doi: 10.1096/fj.05-5399com, PMID 16873885

64. Wiseman RA. Breast cancer: critical data analysis concludes that estrogens are not the cause, however lifestyle changes can alter risk rapidly. J Clin Epidemiol. 2004;57(8):766-72. doi: 10.1016/j.jclinepi.2003.10.017, PMID 15485727.

65. Chan JA, Krichevsky AM, Kosik KS. MicroRNA-21 is an antiapoptotic factor in human glioblastoma cells. Cancer Res. 2005;65(14):6029-33. doi: 10.1158/0008-5472.CAN-05-0137, PMID 16024602.

66. Hammond SM. MicroRNAs as oncogenes. Curr Opin Genet Dev. 2006;16(1):4-9. doi: 10.1016/j.gde.2005.12.005, PMID 16361094.

67. Hayashita $Y$, Osada H, Tatematsu Y, Yamada H, Yanagisawa K, Tomida S, Yatabe Y, Kawahara K, Sekido Y, Takahashi T. A polycistronic microRNA cluster, miR-17-92, is overexpressed in human lung cancers and enhances cell proliferation. Cancer Res. 2005;65(21):9628-32. doi: 10.1158/00085472.CAN-05-2352, PMID 16266980.

68. Johnson SM, Grosshans H, Shingara J, Byrom M, Jarvis R, Cheng A, Labourier E, Reinert KL, Brown D, Slack FJ. RAS is regulated by the let-7 microRNA family. Cell. 2005;120(5):635-47. doi: 10.1016/j.cell.2005.01.014, PMID 15766527.

69. Verghese ET, Hanby AM, Speirs V, Hughes TA. Small is beautiful: microRNAs and breast cancer-where are we now? J Pathol. 2008;215(3):214-21. doi: 10.1002/path.2359. Society of Great Britain and Ireland. 2008;215(3):214-21.

70. Iorio MV, Ferracin M, Liu CG, Veronese A, Spizzo R, Sabbioni S, Magri E, Pedriali M, Fabbri M, Campiglio M, Ménard S, Palazzo JP, Rosenberg A, Musiani P, Volinia S, Nenci I, Calin GA, Querzoli P, Negrini M, Croce CM. MicroRNA gene expression deregulation in human breast cancer. Cancer Res. 2005;65(16):7065-70. doi: 10.1158/0008-5472.CAN-05-1783, PMID 16103053.

71. Mattie MD, Benz CC, Bowers J, Sensinger K, Wong L, Scott GK, Fedele V, Ginzinger D, Getts R, Haqq C. Optimized high-throughput microRNA expression profiling provides novel biomarker assessment of clinical prostate and breast cancer biopsies. Mol Cancer. 2006;5(1):24. doi: 10.1186/14764598-5-24, PMID 16784538.

72. Tavazoie SF, Alarcón C, Oskarsson T, Padua D, Wang Q, Bos PD, Gerald WL, Massagué J. Endogenous human microRNAs that suppress breast cancer metastasis. Nature. 2008;451(7175):147-52. doi: 10.1038/nature06487, PMID 18185580.

73. Gusev Y, Schmittgen TD, Lerner M, Postier R, Brackett D. Computational analysis of biological functions and pathways collectively targeted by co-expressed microRNAs in cancer. BMC Bioinformatics. 2007;8(7):1-17. doi: 10.1186/1471-2105-8-S7-S16, PMID 18047715.

74. Si ML, Zhu S, Wu H, Lu Z, Wu F, Mo YY. miR-21-mediated tumor growth Oncogene. 2007;26(19):2799-803. doi: 10.1038/sj.onc.1210083, PMID 17072344.

75. Lu Z, Liu M, Stribinskis V, Klinge CM, Ramos KS, Colburn NH, Li Y. MicroRNA-21 promotes cell transformation by targeting the programmed cell death 4 gene. Oncogene. 2008;27(31):4373-9. doi: 10.1038/onc.2008.72, PMID 18372920.

76. Hossain A, Kuo MT, Saunders GF. Mir-17-5p regulates breast cancer cell proliferation by inhibiting translation of AIB1 mRNA. Mol Cell Biol. 2006;26(21):8191-201. doi: 10.1128/MCB.00242-06, PMID 16940181.

77. Scott GK, Goga A, Bhaumik D, Berger CE, Sullivan CS, Benz CC. Coordinate suppression of ERBB2 and ERBB3 by enforced expression of micro-RNA miR-125a or miR-125b. J Biol Chem. 2007;282(2):1479-86. doi: 10.1074/jbc. M609383200, PMID 17110380.

78. Adams BD, Furneaux H, White BA. The micro-ribonucleic acid (miRNA) miR-206 targets the human estrogen receptor-alpha (ERalpha) and represses ERalpha messenger RNA and protein expression in breast cancer cell lines. Mol Endocrinol. 2007;21(5):1132-47. doi: 10.1210/me.2007-0022, PMID 17312270. 
PICTORIAL ABSTRACT

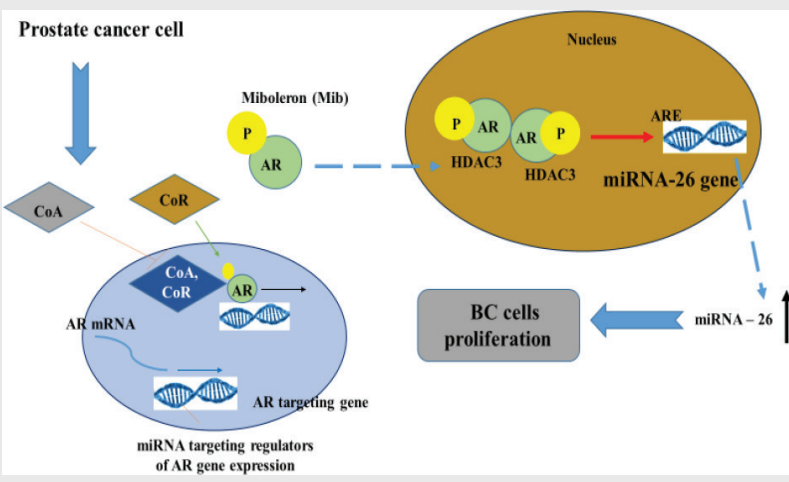

SUMMARY

MiR-26 is a miRNA tumour suppressor that is frequently dysregulated in many tumour tissues and lines of tumour cells. This review summarizes the role of AR \& E evolving as a target to scrutinize amongst hormone receptors. Because, it seems to show a diverse stage of development in the breast and prostate cancers. Keeping this in mind, AR and ER is becoming very pertinent in current times. Though its role in medical treatment remains difficult, numerous findings have established a link between microRNAs 26, a class of genetic expression receptors and cancer, yet there is currently little confirmation for a link between BC and PC miRNAs. The major goal of this research is to present an AR and ER route implicated in microRNA production 26 . In addition, the functional and structural characterization of microRNAs 26 in cancer and non-cancerous cells was briefly mentioned. Furthermore, the gene for post-transcriptional regulatory roles of distinct defective miRNAs 26 in breast and prostate cancer, as well as their therapeutic potential, were found.

Cite this article: Fattepur S, Sreeharsha N, Anwer Md. K, Asdaq SMB, Nilugal KC, Abdullah I. Coordinated Androgen and Estrogen-receptor microRNA 26 Directive in Breast and Prostate Tumour. Indian J of Pharmaceutical Education and Research. 2021;55(3):738-47. 